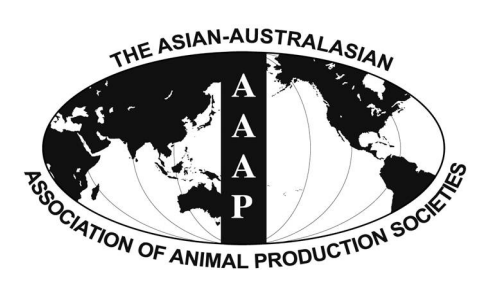

Open Access

Asian Australas. J. Anim. Sci.

Vol. 29, No. 12 : 1702-1709 December 2016

http://dx.doi.org/10.5713/ajas.15.1037

www.ajas.info

pISSN 1011-2367 elSSN 1976-5517

\title{
Molecular Cloning, mRNA Expression, and Localization of the G-protein Subunit Galphaq in Sheep Testis and Epididymis
}

\author{
Zhen $\mathrm{Li}^{1,2}$, Jieli Lu ${ }^{1,2}$, Xiaowei Sun ${ }^{1,2}$, Quanhai Pang ${ }^{1, *}$, and Yiwen Zhao ${ }^{1,2}$ \\ ${ }^{1}$ College of Animal Science and Technology, Shanxi Agricultural University, Taigu 030801, China
}

\begin{abstract}
The reproductive function of G-protein subunit Galphaq (GNAQ), a member of the G protein alpha subunit family, has been extensively studied in humans and rats. However, no data is available on its status in ruminants. The objectives of this study were to evaluate the expression pattern of the GNAQ in the testis and epididymis of sheep by polymerase chain reaction (PCR). The mRNA expression levels were detected by real-time fluorescent quantitative PCR, and cellular localization of GNAQ in the testis and epididymis was examined by immunohistochemistry. Additionally, GNAQ protein was qualitatively evaluated via western blot, with the results indicating that similarities between GNAQ mRNA levels from sheep was highly conserved with those observed in Bos taurus and Sus scrofa. Our results also indicated that GNAQ exists in the caput and cauda epididymis of sheep, while GNAQ in the testis and epididymis was localized to Leydig cells, spermatogonial stem cells, spermatocytes, Sertoli cells, spermatid, principal cells, and epididymis interstitial cells. The concentrations of GNAQ mRNA and protein in the caput and cauda epididymis were significantly greater than those observed in the corpus epididymis $(\mathrm{p}<0.01)$ and testis $(\mathrm{p}<0.05)$. Our results indicated that GNAQ exists at high concentrations in the caput and cauda epididymis of sheep, suggesting that GNAQ may play an important role in gonad development and sperm maturation. (Key Words: Epididymis, G-protein Subunit Galphaq [GNAQ], Sheep, Testis)
\end{abstract}

\section{INTRODUCTION}

G protein-coupled receptors (GPCRs) are a large and diverse group of receptors consisting of seven transmembrane domains with affinity for a multitude of ligands, such as hormones, odorants, and light (Schappi et al., 2014). GPCRs are composed of $\alpha-, \beta-$, and $\gamma$-subunits, and in humans there are $21 \mathrm{G} \alpha$ subunits encoded by 16 genes, six $\mathrm{G} \beta$ subunits encoded by five genes, and $12 \mathrm{G} \gamma$ subunits (Downes et al., 1999). The $\mathrm{G} \alpha$ subunits have been divided into five different families, specifically Gs, Gi, Gq, G12 (Simon et al., 1991), and Gv (Oka et al., 2009). The Gq class is one subfamily of the $G$ protein alpha subunit family and is comprised of four genes: G-protein subunit Galphaq (GNAQ), GNA11, GNA14, and GNA15 (Davignon et al., 1996; Chen et al., 2008).

\footnotetext{
* Corresponding Author: Quanhai Pang. Tel: +86-134-5323 0899, Fax: +86-354-6286-586, E-mail: pangquanhai@163.com

${ }^{2}$ Lab of China clinical veterinary, Shanxi Agricultural University, Taigu 030801, China.

Submitted Dec. 18, 2015; Revised Feb. 6, 2016; Accepted Mar. 15, 2016
}

Previous northern hybridization studies confirmed that Galphaq mRNA was highly expressed in human tissues and organs associated with the human reproductive system, including the ovaries, prostate glands, and testes (Chen et al., 1996). In mice and humans, tissue distribution analysis showed that GNAQ and GNA11 were co-expressed in the liver, heart, muscle, spleen, adipose tissue, brain, and uterus (Chen et al., 2008). In rat germ cells, immunohistochemistry verified that $\mathrm{GQ} / 11$ localized in the seminiferous tubules, and that the somatic cells (Sertoli cells, peritubular cells) contained high concentrations of both $\mathrm{Gq} / 11 \alpha$ mRNA and immunoreactive protein (Haugen et al., 1993). Immunohistochemical analyses have found that Galpha12 is expressed in the cytoplasm of Leydig cells of human testes, as well as in spermatids from the elongating $\mathrm{Sb}$ phase to mature sperms (Hu et al., 2006). Galpha12, Galpha13, and Galpha11 (GNA12, GNA13, and GNA11) also localized in spermatogenic cells and Leydig cells (Hu et al., 2008). In rat testicular cells, $G$ protein $\alpha$-subunits and their mRNA were expressed in pachytene spermatocytes, round spermatids, Sertoli cells, and peritubular cells (Paulssen et 
al., 1991). In male rats, GQ/11 $\alpha$ subunits were found to be expressed in epididymal adipose tissue (Denis-Henriot et al., 1996).

Although the reproductive function of GNAQ in humans and rats has been studied (Table 1), there is no data available on its status in ruminants, specifically in ruminant epididymis. The objective of this study was to determine the difference between GNAQ mRNA and Gnaq protein expression levels in the caput, corpus, and cauda epididymis and testes of sheep. Here, GNAQ mRNA expression levels were detected by real-time fluorescent quantitative polymerase chain reaction (PCR), and the cellular localization of GNAQ in caput, corpus, and cauda epididymis and testis was examined by immunohistochemistry. Quantitative investigation of the GNAQ protein was analyzed by western blot and quantitative real-time PCR. Our findings may help signify the role of the GNAQ protein in gonad development.

\section{MATERIALS AND METHODS}

\section{Animals}

Testes and epididymis were collected from six healthy adult Texel sheep (IACUC\#14-022) with an average body weight of $44.5 \pm 0.5 \mathrm{~kg}$ at the breeding base of Shanxi Agricultural University.

\section{RNA isolation and cDNA synthesis}

Total RNA was extracted by TRIzol (TaKaRa Bio Co. Ltd., Dalian, China) from the testis, caput, corpus, and cauda epididymis of six sheep according to the method described by Shi et al. (2010). The total RNA concentrations were quantified using a ND-1000 spectrophotometer (Nanodrop Technologies, Wilmington, DE, USA), and then dissolved in diethylpyrocarbonatetreated distilled water and stored at $-80^{\circ} \mathrm{C}$ until cDNA synthesis. The total RNA of the testis, caput, corpus, and cauda epididymis was reverse transcribed into cDNA using a PrimeScript RT Master Mix Perfect Real Time kit (TaKaRa Bio Co. Ltd., China). The $10 \mu \mathrm{L}$ reaction mixture contained $2 \mu \mathrm{L} 5 \times$ PrimeScript buffer, $1 \mu \mathrm{L}$ total RNA, and $7 \mu \mathrm{L}$ RNase-free $\mathrm{ddH}_{2} \mathrm{O}$. The reaction conditions were $37^{\circ} \mathrm{C}$ for $15 \mathrm{~min}$, followed by $85^{\circ} \mathrm{C}$ for $5 \mathrm{~s}$. The reverse transcription product was stored at $-20^{\circ} \mathrm{C}$ until use.

\section{Cloning of partial GNAQ cDNA}

The primers were designed and synthesized by using testis and epididymis cDNA. A forward primer (5'AATCCAGGAATGCTATGAC-3') and a reverse primer (5'AGGCACGACTAGACCAGA-3') were designed based on reference sequences from Bos taurus GNAQ mRNA (GenBank accession no. NM_001110002.1). The sheep testes and epididymis cDNA were amplified by PCR using TaKaRa Ex Taq kit (TaKaRa Bio Co. Ltd., China). The 10 $\mu \mathrm{L}$ reaction mixture contained $1.5 \mu \mathrm{L} 10 \times$ PCR buffer, 1.2 $\mu \mathrm{L} 10 \mathrm{mmol} / \mathrm{L}$ dNTP mixture, $0.3 \mu \mathrm{L}$ TaqDNA polymerase (125 U), $0.6 \mu \mathrm{L} 10 \mu \mathrm{M}$ random primer, $1 \mu \mathrm{L}$ template DNA, and $9.8 \mu \mathrm{L} \mathrm{ddH}_{2} \mathrm{O}$. The thermal cycler program used consisted of 35 cycles at $94^{\circ} \mathrm{C}$ for $3 \mathrm{~min}, 94^{\circ} \mathrm{C}$ for $10 \mathrm{~s}$, $60^{\circ} \mathrm{C}$ for $30 \mathrm{~s}$, and $72^{\circ} \mathrm{C}$ for $30 \mathrm{~s}$. Amplified cDNA were ligated into a $p E A S Y$-T3 Cloning Vector (TransGen Biotech., Beijing, China) overnight at $4^{\circ} \mathrm{C}$. The ligation product of the amplified fragment with the linear vector $p E A S Y$-T3 was then transformed into Trans1-T1 phage-resistant chemically competent cells (TransGen Biotech., China). Plasmids containing the inserts of interest were sequenced.

\section{Immunohistochemistry analysis of GNAQ in testis and epididymis}

Paraffin sections $(5 \mu \mathrm{m})$ of testis and epididymis were deparaffinized and rehydrated in graded ethanol. The polyclonal mouse anti- GNAQ (Biosynthesis Bio Co., Ltd., Beijing, China) antibody was used for the immunolocalization studies. The deparaffinized sections were incubated with mouse anti- GNAQ diluted 1:100 in $0.01 \mathrm{M}$ phosphate-buffered saline (PBS; $\mathrm{pH}$ 7.2) overnight at $4^{\circ} \mathrm{C}$. After being washed with PBS, sections were treated with polymerized horseradish peroxidase (HRP)-conjugated secondary antibody (Boster Co. Ltd., Wuhan, China) and streptavidin-biotin complexes (Boster Co. Ltd., China) for 30 min. They were then washed three times with PBS for 5 min each. Immunoreactivity was visualized using 3diaminobenzidine and examined under microscope. For negative controls, the slides were incubated overnight with non-immune bovine serum (Boster Co. Ltd., China) instead of the primary antibody.

Table 1. G proteins $\alpha$-subunits were expressed in male sex organ

\begin{tabular}{lcl}
\hline Genes & Animals/Humans & \multicolumn{1}{c}{ Expression } \\
\hline$G N A Q$ & Human & Ovaries, prostate glands, and testes \\
$G N A Q / 11$ & Rat & Germ cells \\
$G N A 12$ & Human & Testes \\
& Rat & Spermatogenic cells and Leydig cells \\
$G N A 13$ & Rat & Spermatogenic cells and Leydig cells \\
G proteins $\alpha$-subunits & Rat & Pachytene spermatocytes, round spermatids, Sertoli cells, peritubular cells \\
\hline
\end{tabular}

$G N A Q, G$-protein subunit Galphaq. 


\section{Quantitative real-time PCR}

Prior to cDNA synthesis, the total RNA without genomic DNA was diluted to the same concentration. All PCR reactions were performed in duplicate in an Mx3005P real-time thermal cycler (Stratagene, La Jolla, CA, USA) using a SYBR Permix Ex Taq kit (TaKaRa Bio Co. Ltd., China) according to manufacturer instructions. The extracted plasmids containing inserts of the GNAQ fragment were diluted to eight different concentrations in order to construct standard plasmid samples. According to the method used to determine plasmid copy number [plasmid copy number $($ copies $/ \mu \mathrm{L})=6.02 \times 10^{23}$ (copies $/ \mathrm{mol}) \times$ plasmid concentration $(\mathrm{g} / \mu \mathrm{L}) /($ DNA length $\times 660)$ ], standard plasmid samples were created according to the copy number in the quantitative PCR reaction $($ copies $/ \mu \mathrm{L}): 3.80 \times 10^{10}, \quad 3.80 \times 10^{9}, \quad 3.80 \times 10^{8}, \quad 3.80 \times 10^{7}$, $3.80 \times 10^{6}, 3.80 \times 10^{5}, 3.80 \times 10^{4}$, and $3.80 \times 10^{3}$. The forward primer (20 nt) of the GNAQ gene was 5'-CTCAGA GTTCGAGTCCCCAC-3', and the reverse primer (20 nt) of the GNAQ gene was 5'-AGTTCTGGAACCAGGGATACG$3^{\prime}$. The thermal cycler program consisted of 45 cycles of $95^{\circ} \mathrm{C}$ for $10 \mathrm{~s}$, and $60^{\circ} \mathrm{C}$ for $25 \mathrm{~s}$. Quantitative results were calculated according to a standard curve.

\section{Western blot analysis}

Total protein was extracted from the testis, caput, corpus, and cauda epididymis. Before homogenizing the tissues in Tissue Protein Extraction Reagent (Boster Co. Ltd., China), we supplemented the reagent with phenylmethanesulfonyl fluoride (Boster Co. Ltd., China). After a 30 min incubation at $4^{\circ} \mathrm{C}$, samples were centrifuged at $12,000 \mathrm{~g}$ for $10 \mathrm{~min}$ at $4^{\circ} \mathrm{C}$. The supernatant was collected and saved at $-80^{\circ} \mathrm{C}$ until use. Protein concentrations were measured by the bicinchoninic-acid assay method using bovine serum albumin (Solarbio Science \& Technology Co. Ltd., Beijing, China) as the standard.

Total protein extracts $(100 \mu \mathrm{g})$ were separated on sodium dodecyl sulfate polyacrylamide gels and transferred onto nitrocellulose membranes (Boster Co. Ltd., China). The membranes were incubated with primary antibodies against GNAQ (1:300) and rabbit anti- $\beta$-actin (1:300) for 2 $\mathrm{h}$ at $37^{\circ} \mathrm{C}$. After exposure to primary antibodies, the membranes were washed and incubated in HRP-conjugated goat anti-mouse $\operatorname{IgG}(1: 10,000$; Boster Co. Ltd., China) and donkey anti-rabbit IgG (1:10,000; Boster Co. Ltd., China) for $1 \mathrm{~h}$ at room temperature. The membranes were then washed three times (10 min each) using Tris-buffered saline and Tween $20[140 \mathrm{mM} \mathrm{NaCl}, 20 \mathrm{mM}$ Tris- $\mathrm{HCl}(\mathrm{pH} 7.5)$, $0.05 \%$ Tween $20(\mathrm{v} / \mathrm{v})]$, proteins detected using an eECL Western Blot kit (CWBIO Co. Ltd., Beijing, China), and images exposed by FluoChem Q Gel Image Acquisition and Analysis System. All experiments were performed in triplicate.

\section{Statistical analysis}

All data were analyzed using SPSS 17.0 software program (SPSS Inc., Chicago, IL, USA), and presented as the mean \pm standard error of mean. A one-way analysis of variance was used to determine statistical differences in the data. All results were expressed as mean \pm standard deviation and $\mathrm{p}<0.05$ was considered statistically significant.

\section{RESULTS}

\section{Cloning of partial GNAQ cDNA from sheep testes and epididymis}

The GNAQ cDNA fragment (672 bp) was detected in sheep testis, caput, corpus, and cauda epididymis. Sequences of this fragment were uploaded to the National Center of Biotechnology Information (GenBank accession number: KP940628). This sequence was compared with those of Bos taurus, Sus scrofa, Homo sapiens, Mus musculus, Rattus norvegicus, and Gallus gallus (Figure 1A). The results showed high degrees of homology between species: Bos taurus (97.92\%), Sus scrofa (94.65\%), Homo sapiens (94.35\%), Mus musculus (92.57\%), Rattus norvegicus $(91.08 \%)$, and Gallus gallus (86.22\%).

In order to examine the relationships of GNAQ between various organisms, a phylogenetic tree of GNAQ mRNA from sheep and other species were constructed (Figure 1B). The topology of the tree demonstrated that the sheep GNAQ mRNA sequence was highly conserved within Bos taurus and Sus scrofa.

\section{GNAQ protein immunohistochemistry}

GNAQ protein localization in the testis and epididymis was determined by immunohistochemistry. In the testis, GNAQ protein was localized to Leydig cells, spermatogonial stem cells, spermatocytes, Sertoli cells, and spermatid (Figure 2A). In caput, corpus, and cauda epididymis, GNAQ expression was detected in principal cells and epididymis interstitial cells (Figure 2C, 2E, and $2 \mathrm{G})$.

\section{GNAQ mRNA levels in testis and epididymis}

The GNAQ standard curve had a slope of $-3.331\left(\mathrm{R}^{2}=\right.$ 0.992) and established a measurement amplification efficiency of $99.6 \%$ (Figure 3A). These results indicated that the quantification method used was effective. Figure 3B displays the GNAQ mRNA expression in different tissues (copies $/ \mu \mathrm{L}$ ): $1.19 \times 10^{5}, 4.63 \times 10^{5}, 5.06 \times 10^{5}$, and $2.66 \times 10^{5}$. A significant difference was observed in the expression levels of GNAQ mRNA in caput and cauda epididymis. 


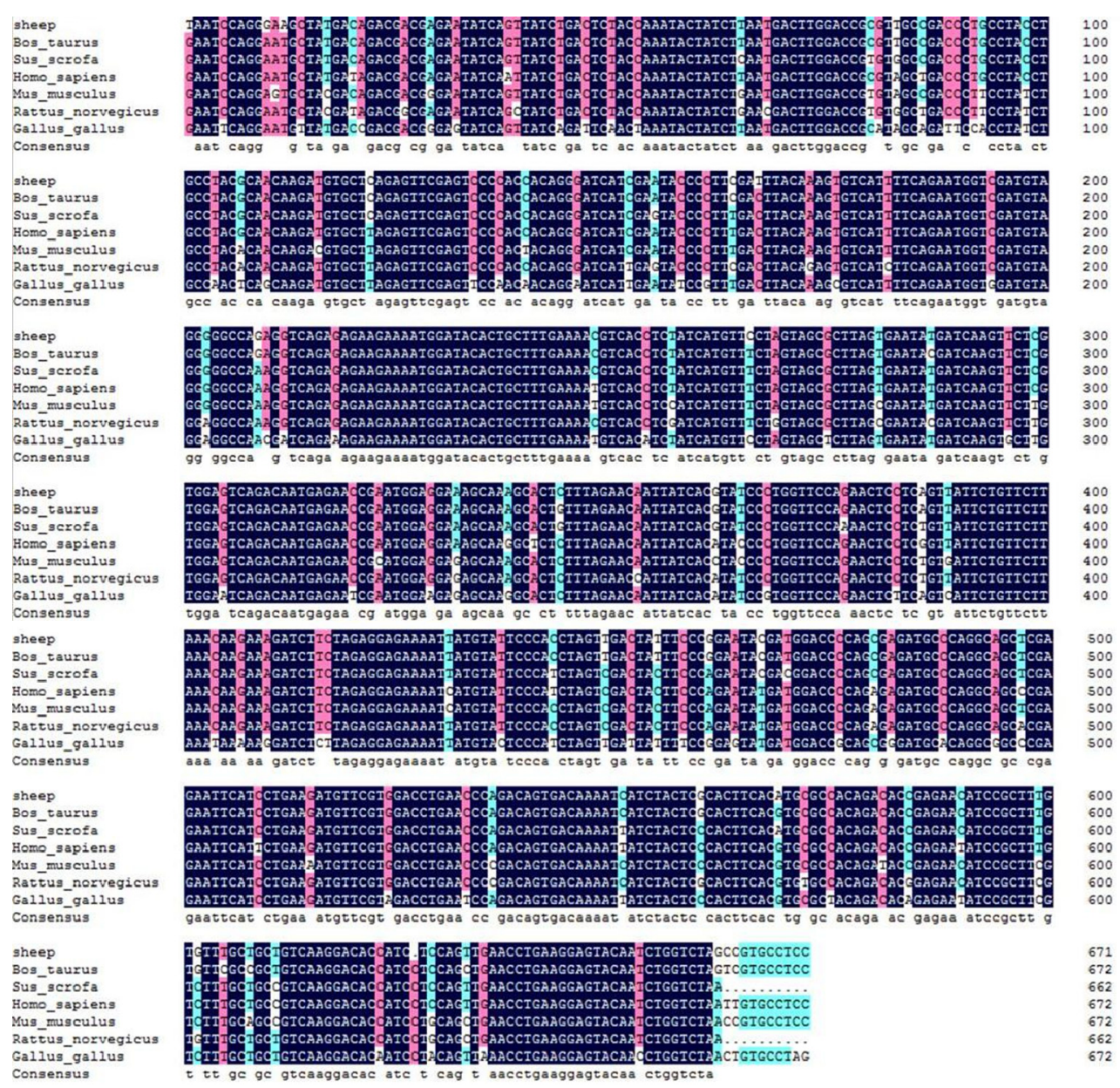

(A)

$100 \% 95 \% \quad 90 \% \quad 85 \% \quad 80 \% \quad 75 \% \quad 70 \%$

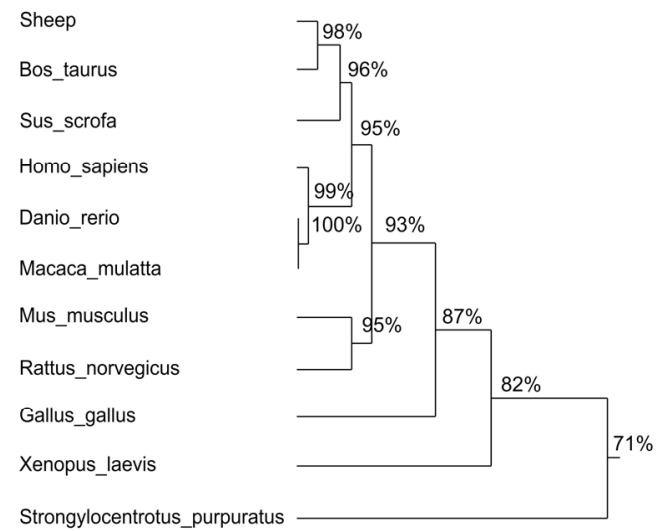

(B)

Figure 1. (A) Homology analysis of G-protein subunit Galphaq (GNAQ) from different species. GNAQ cDNA sequences of sheep, Bos taurus, Sus scrofa, Homo sapiens, Mus musculus, Rattus norvegicus, and Gallus gallus were analyzed. (B) Phylogenetic analysis of sheep relative to other organism homologues. Sequence alignment of GNAQ cDNA was processed using DNAMAN v6 (Lynnon Biosoft, San Ramon, CA, USA).

GNAQ protein levels in testis and epididymis

GNAQ protein levels were analyzed by western blot. As shown in Figure 4A, the GNAQ protein (42 kDa) was detected in the total protein extracted from caput, corpus, and cauda epididymis and testis. The GNAQ protein levels in the caput and cauda epididymis were significantly greater than those observed in the corpus epididymis $(p<0.01)$ and testis $(\mathrm{p}<0.05)$ (Figure 4B). The GNAQ protein level was 
A

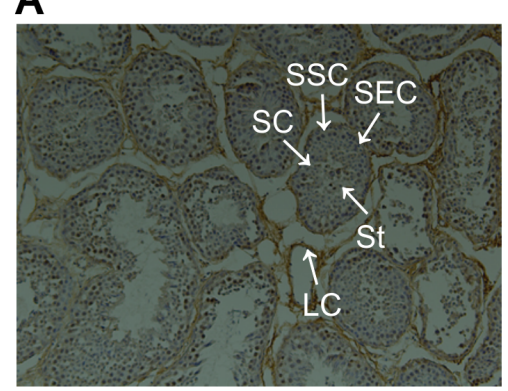

C

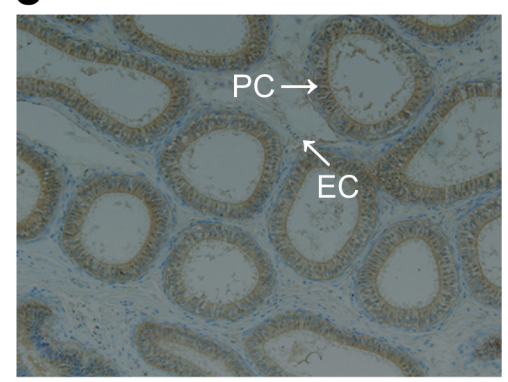

E

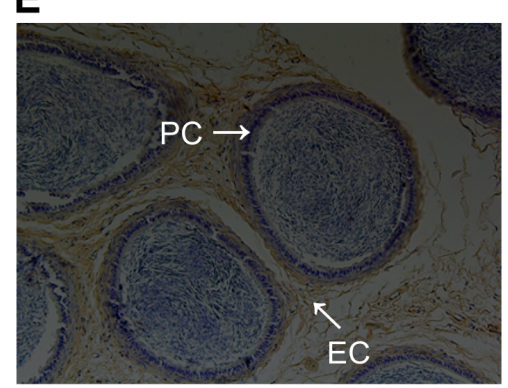

G

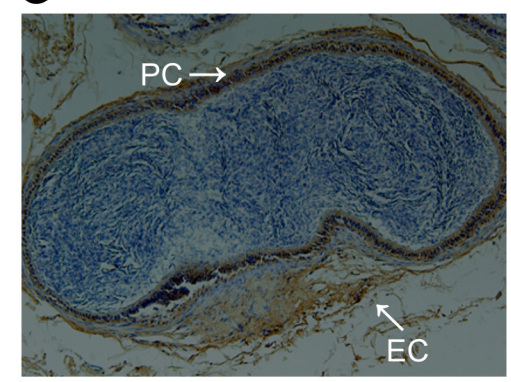

B

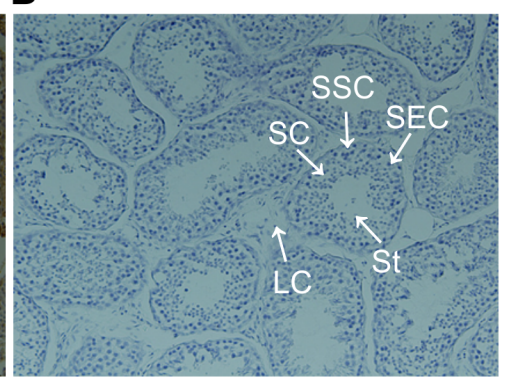

D

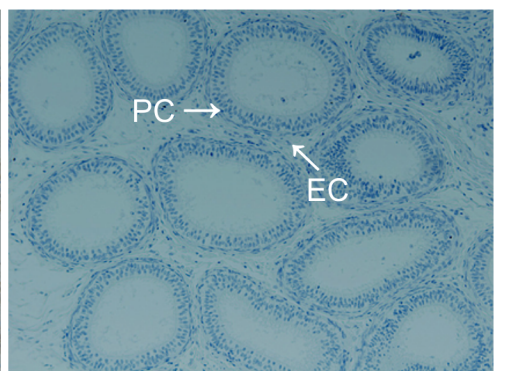

$\mathbf{F}$

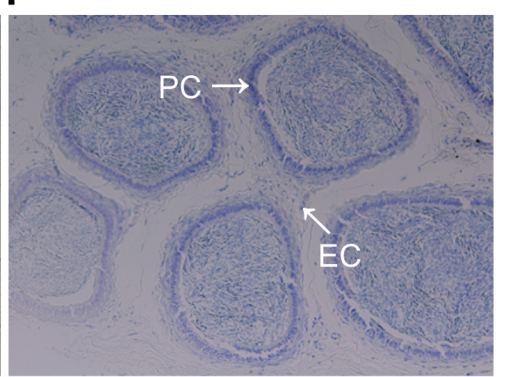

H

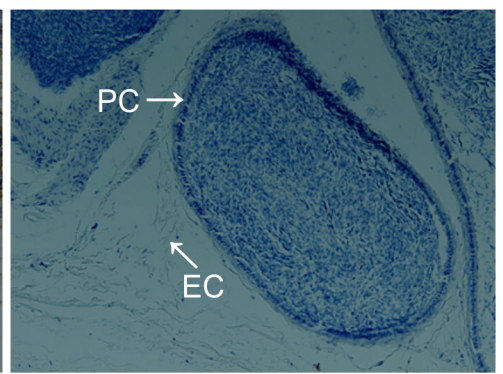

Figure 2. Immunohistochemical localization of the G-protein subunit Galphaq (GNAQ) protein within sheep testis and epididymis. (A) Section of normal sheep testis incubated with mouse anti- GNAQ serum. GNAQ protein was localized to Leydig cells (LC), spermatogonial stem cells (SSC), spermatocytes (SC), Sertoli cells (SEC), and spermatid (St). (B) Section of normal sheep testis incubated with normal rabbit serum (C, E, and G). Section of normal sheep caput, corpus, and cauda epididymis incubated with rabbit anti- GNAQ serum. GNAQ protein was localized to principal cells (PC) and epididymis interstitial cells (EC). (D, F, and H) Section of normal sheep caput, corpus, and cauda epididymis incubated with normal mouse serum. (A-H) Magnification, $100 \times$; scale bar, $300 \mu \mathrm{m}$.

consistent with the mRNA expression levels determined from the different sheep.

\section{DISCUSSION}

In recent years, the effects of $G$ protein on male reproduction are of high concern. As a family of $\mathrm{G}$ proteins, estrogen-associated G protein-coupled receptor 30 (GPR30) was detected in many human tissues, including ovary and prostate (Prossnitz et al., 2008). Other studies showed that GPR30 had also been found in human (Rago et al., 2011) and rodent testes (Otto et al., 2009). These results implied that $\mathrm{G}$ protein played an important role in animal reproductive systems. In view of our observations of GNAQ expression in caput, corpus, and cauda epididymis and testes, we speculated that GNAQ may play a role in 

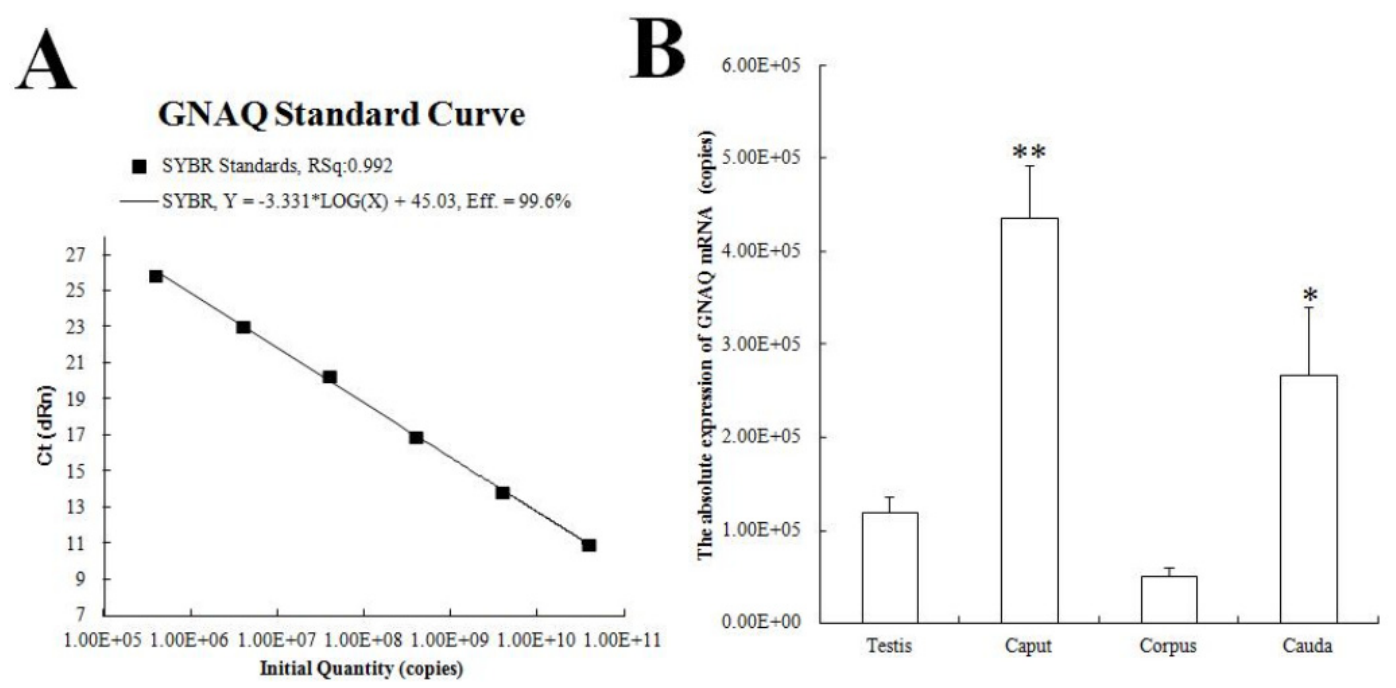

Figure 3. The GNAQ standard curve and the expression of G-protein subunit Galphaq (GNAQ) mRNA in different tissues. (A) The GNAQ standard curve; (B) the absolute expression of GNAQ mRNA in caput, corpus, and cauda epididymis and testis.

estrogen signaling associated with germ-cell differentiation, and that this role may be dependent upon the progression stage of the spermatogenic event.

$\mathrm{G}$ protein $\alpha$-subunit family members were first identified using affinity purification (Pang and Sternweis, 1989; 1990) and molecular cloning strategies (Strathmann and Simon, 1990; 1991). GNAQ expression has been observed in the spleen, lung, kidney, pancreas, liver, testis, and bone-marrow adherent stromal cells (Nakamura et al., 1991; Wilkie et al., 1991; Zigman et al., 1994). The results of our study showed that GNAQ mRNA was expressed in caput, corpus, and cauda epididymis and testes, but abundantly expressed in caput and cauda epididymis. Subsequently, semi-quantitative analysis (i.e., western blot) revealed that the level of GNAQ protein expression was similar to that observed for GNAQ mRNA expression. Using northern and western blot techniques, Haugen et al.
(1993) found that GNAQ mRNA levels were low in germ cells and primarily observed in somatic cells of testis. Additionally, the mRNA expression levels agreed with the observed levels of immunoreactive proteins, which was similar to the results presented here. In human testis, Zigman et al. (1994) and Chen et al. (1996) both found evidence of GNAQ mRNA expression.

In male animals, Leydig cells are responsible for testosterone production and secretion (Shan et al., 1997), we found that in testis, the GNAQ protein localized to Leydig cells, spermatogonial stem cells, spermatocytes, Sertoli cells, and spermatid. This result may provide further evidence that Sertoli cells are involved in regulating spermatogenesis and testicular function (Boukenaoui et al., 2012). Therefore it is possible that GNAQ can affect testosterone production. Furthermore, our results were similar to those outlining protein and mRNA expression in

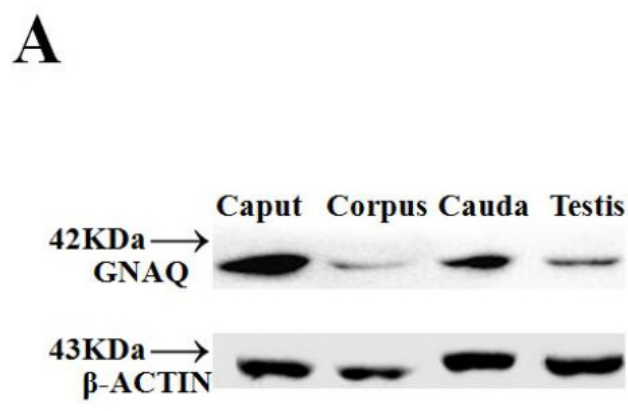

B

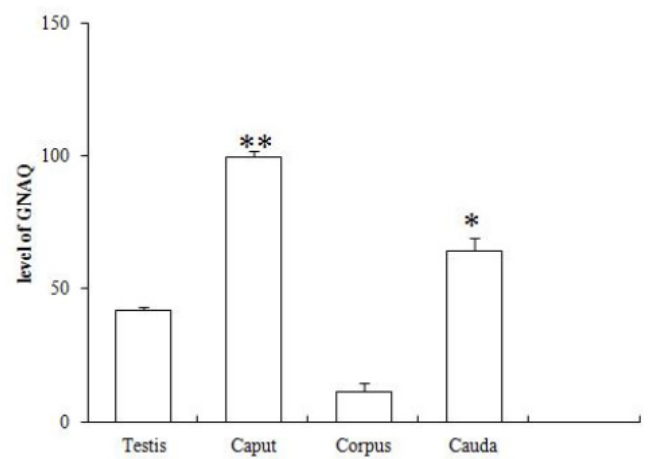

Figure 4. Western blot analysis of G-protein subunit Galphaq (GNAQ) protein expression in the caput, corpus, and cauda epididymis and testis. (A) Western blot results for GNAQ protein in the caput, corpus, and cauda epididymis and testis. (B) Relative GNAQ protein expression levels in caput, corpus, and cauda epididymis and testis. Bars in panel represent the mean \pm standard deviation ( $\mathrm{n}=3$ ); ** $\mathrm{p}<0.01, * \mathrm{p}<0.05$. 
human testis, specifically involving confirmation that GNA12 protein was expressed in the cytoplasm of Leydig cells and mature sperm (Hu et al., 2006).

Sertoli cells are the major component of blood-testis barrier; its main function is to nourish the developing sperm cells through the stages of spermatogenesis and secret many bioactive factors to affect spermatogenesis. The present studies showed that GNAQ exists in Sertoli cells; therefore it is possible that it can affect the fuction of Sertoli cells. However, the mechanisms involved in the regulation of spermatogonial stem cells, spermatocytes, and spermatid proliferation and differentiation have not been elucidated. Therefore, GNAQ affects testosterone production in male sheep that need for further study.

In summary, the results of present studies demonstrated that GNAQ exists in testis and epididymis. We also showed that GNAQ was necessary for indirect regulation of spermatogenesis by Sertoli cells and principal cells. We have confirmed that sheep GNAQ was widely expressed in the epididymis and testes. Perhaps it can improve ram fertility by affecting spermatogenesis and sperm motility. Hence, we suggest that GNAQ may play an important role in gonad development and sperm maturation. However, the specific mechanisms associated with these functions require further research.

\section{CONFLICT OF INTEREST}

We certify that there is no conflict of interest with any financial organization regarding the material discussed in the manuscript.

\section{ACKNOWLEDGMENTS}

The authors are grateful to everyone who helped in this work. This work was supported by National Natural Science Foundation of China (NO.30972223, 31272628); Postgraduate Education Innovation Project of Shanxi Province under Grant (Number 2016BY070).

\section{REFERENCES}

Boukenaoui, N., E. Moudilou, C. Chevalier, Z. Amirat, J. M. Exbrayat, and F. Khammar. 2012. Postnatal changes in testicular development and androgen receptors immunolocalization in D'Man ram lambs. Folia Histochem. Cytobiol. 50:38-45.

Chen, B., R. D. Leverette, V. A. Schwinn, and M. M. Kwatra. 1996. Human G (alpha q): cDNA and tissue distribution. Biochim. Biophys. Acta. 1281:125-128.

Chen, H., W. Yao, D. Jin, T. Xia, X. Chen, T. Lei, L. Zhou, and Z. Yang. 2008. Cloning, expression pattern, chromosomal localization, and evolution analysis of porcine Gnaq, Gnall, and Gna14. Biochem. Genet. 46:398-405.

Davignon, I., M. Barnard, O. Gavrilova, K. Sweet, and T. M. Wilkie. 1996. Gene structure of murine Gnall and Gnal5: tandemly duplicated $\mathrm{Gq}$ class $\mathrm{G}$ protein $\alpha$ subunit genes. Genomics 31:359-366.

Denis-Henriot, D., D. Lacasa, P. K. Goldsmith, P. De Mazancourt, and Y. Giudicelli. 1996. Site-related differences in G protein $\alpha$ subunit expression during adipogenesis in vitro: possible key role for $\mathrm{Gq} / 11 \alpha$ in the control of preadipocyte differentiation. Biochem. Biophys. Res. Commun. 220:443-448.

Downes, G. B. and N. Gautam. 1999. The G protein subunit gene families. Genomics 62:544-552.

Haugen, T. B., R. H. Paulssen, and V. Hansson. 1993. Cell-specific expression of $\mathrm{Gq} / 11$ protein and mRNA in rat seminiferous tubules. FEBS Lett. 329:96-98.

Hu, Y., Y. Lu, Z. Zhou, Y. Du, J. Xing, L. Wang, M. Lin, and J. Sha. 2006. Defective expression of $\mathrm{G} \alpha 12$ in the testes of azoospermia patients and in the spermatozoa with low motility. J. Mol. Med. 84:416-424.

Hu, Y., J. Xing, L. Chen, X. Guo, Y. Du, C. Zhao, Y. F. Zhu, M. Lin, Z. M. Zhou, and J. H. Sha. 2008. RGS22, a novel testisspecific regulator of G-protein signaling involved in human and mouse spermiogenesis along with GNA12/13 subunits. Biol. Reprod. 79:1021-1029.

Nakamura, F., K. Ogata, K. Shiozaki, K. Kameyama, K. Ohara, T. Haga, and T. Nukada. 1991. Identification of two novel GTPbinding protein alpha-subunits that lack apparent ADPribosylation sites for pertussis toxin. J. Biol. Chem. 266:12676-12681.

Oka, Y., L. R. Saraiva, Y. Y. Kwan, and S. I. Korsching. 2009. The fifth class of $\mathrm{G} \alpha$ proteins. Proc. Natl. Acad. Sci. USA. 106:1484-1489.

Oliveira, P. F., M. G. Alves, A. D. Martins, S. Correia, R. L. Bernardino, J. Silva, A. Barros, M. Sousa, J. E. Cavaco, and S. Socorro. 2014. Expression pattern of $\mathrm{G}$ protein-coupled receptor 30 in human seminiferous tubular cells. Gen. Comp. Endocrinol. 201:16-20.

Otto, C., I. Fuchs, G. Kauselmann, H. Kern, B. Zevnik, P Andreasen, G. Schwarz, H. Altmann, M. Klewer, M. Schoor, R. Vonk, and K. H. Fritzemeier. 2009. GPR30 does not mediate estrogenic responses in reproductive organs in mice. Biol. Reprod. 80:34-41.

Pang, I. H. and P. C. Sternweis. 1989. Isolation of the alpha subunits of GTP-binding regulatory proteins by affinity chromatography with immobilized beta gamma subunits. Proc. Natl. Acad. Sci. USA. 86:7814-7818.

Pang, I. H. and P. C. Sternweis. 1990. Purification of unique alpha subunits of GTP-binding regulatory proteins (G proteins) by affinity chromatography with immobilized beta gamma subunits. J. Biol. Chem. 265:18707-18712.

Paulssen, R. H., E. J. Paulssen, J. O. Gordeladze, V. Hansson, and T. B. Haugen. 1991. Cell-specific expression of guanine nucleotide-binding proteins in rat testicular cells. Biol. Reprod. 45:566-571.

Prossnitz, E. R., J. B. Arterburn, H. O. Smith, T. I. Oprea, L. A. Sklar, and H. J. Hathaway. 2008. Estrogen signaling through the transmembrane $\mathrm{G}$ protein-coupled receptor GPR30. Annu. Rev. Physiol. 70:165-190. 
Rago, V., F. Romeo, F. Giordano, M. Maggiolini, and A. Carpino. 2011. Identification of the estrogen receptor GPER in neoplastic and non-neoplastic human testes. Reprod. Biol. Endocrinol. 9:135.

Schappi, J. M., A. Krbanjevic, and M. M. Rasenick. 2014. Tubulin, actin and heterotrimeric $\mathrm{G}$ proteins: Coordination of signaling and structure. Biochim. Biophys. Acta 1838:674-681.

Shan, L. X., C. W. Bardin, and M. P. Hardy. 1997. Immunohistochemical analysis of androgen effects on androgen receptor expression in developing Leydig and Sertoli cells. Endocrinology 138:1259-1266.

Shi, L., W. Yue, C. Zhang, Y. Ren, X. Zhu, Q. Wang, and F. Lei. 2010. Effects of maternal and dietary selenium (Se-enriched yeast) on oxidative status in testis and apoptosis of germ cells during spermatogenesis of their offspring in goats. Anim. Reprod. Sci. 119: 212-218.
Simon, M. I., M. P. Strathmann, and N. Gautam. 1991. Diversity of $\mathrm{G}$ proteins in signal transduction. Science 252:802-808.

Strathmann, M. P. and M. I. Simon. 1990. G protein diversity: A distinct class of alpha subunits is present in vertebrates and invertebrates. Proc. Natl. Acad. Sci. USA. 87:9113-9117.

Strathmann, M. P. and M. I. Simon. 1991. Galpha12 and Galpha13 subunits define a fourth class of $\mathrm{G}$ protein alpha subunits. Proc. Natl. Acad. Sci. USA. 88:5582-5586.

Wilkie, T. M., P. A. Scherle, M. P. Strathmann, V. Z. Slepak, and M. I. Simon. 1991. Characterization of G-protein alpha subunits in the Gq class: expression in murine tissues and in stromal and hematopoietic cell lines. Proc. Natl. Acad. Sci. USA. 88:10049-10053.

Zigman, J. M., G. T. Westermark, J. LaMendola, and D. F. Steiner. 1994. Expression of cone transducin, Gz alpha, and other Gprotein alpha-subunit messenger ribonucleic acids in pancreatic islets. Endocrinology 135:31-37. 